\title{
Excise Taxes with Multiproduct Transactions
}

\author{
By Stephen F. Hamilton*
}

Exchange in retail markets often involves transactions of more than one product at a time, as is the case of consumer purchases at department stores, restaurants, and supermarkets. These purchases are frequently taxed and subject to retail sales or value-added taxes (VAT) that are applied across multiple products at once in a single transaction. What are the implications of excise taxes in markets mediated by multiproduct firms? And to what extent do the results from tax models based on single-product transactions generalize to the case of multiproduct transactions? The efficiency and incidence of excise taxes in noncompetitive markets has been an important theme in the field of public economics since the early analysis by Augustin Cournot (1838) and Knut Wicksell (1896). Yet, in light of the multiproduct nature of most retail transactions, it is surprising to note that virtually everything we know about the effect of excise taxes in oligopoly markets is derived from models with single-product firms.

One reason for the lack of research on taxes in multiproduct oligopoly markets is that the analysis of simultaneous price and product variety choices is complex, and this has limited the scope for designing tractable models. ${ }^{1}$ I examine the effect of excise taxes on multiproduct transactions in this paper by framing a model that is capable of generating comparative statics effects in oligopoly settings in which both prices and the breadth of products available at each retailer are jointly determined. The key feature that provides traction in this framework is a combination of the symmetric substitutes utility structure of A. Michael Spence (1976a, b; 1977) and Avinash K. Dixit and Joseph E. Stiglitz (1977) and the locational preference structure of Steven C. Salop (1979). The locational preference structure allows the strategic interactions between retailers to occur at a highly aggregated level, which insulates these forces from multiproduct composition effects that arise through cross elasticities of demand. This creates a clear separation between the intraretailer and interretailer margins of the model.

I frame the analysis of excise taxes around multiproduct firms that select prices and a breadth of product variety, and consumers who choose where to shop. Consumers derive utility directly from the consumption of individual products and indirectly from the amount of product variety available. The locational attributes of firms themselves also convey value to consumers, as would be the case when consumers select among restaurants based on proximity as well as on prices and the extensiveness of wine lists. All products are taxed and a change in excise tax rates alters equilibrium prices, the equilibrium breadth of product variety available in the market, and, in the free-entry case, the equilibrium number of firms.

An important theme in the tax literature is the extent to which excise taxes shift forward into consumer prices in oligopoly markets. Recent academic interest in this topic parallels the growing policy concern in the United States regarding the distributional consequences of consumption-based taxes and has currency in the long-standing debate in the European Union on tax harmonization. In single-product oligopoly models, Jesus K. Seade (1987), Nicholas H. Stern (1987), and Sofia Delipalla and Michael Keen (1992) show that excise taxes are shifted more than

\footnotetext{
*Department of Economics, California Polytechnic State University, San Luis Obispo, CA 93407 (e-mail: shamilto@ calpoly.edu). I am grateful for comments on previous versions of this paper by Hervé Roche, Eric Fisher, Jason Lepore, Jeff Perloff, Eduardo Zambrano, two anonymous referees, numerous seminar participants, and especially Robert Innes.

${ }^{1}$ For a good discussion of this issue, see Simon P. Anderson and André de Palma (2006).
} 
one-for-one into consumer prices when demand is sufficiently convex. Recent empirical evidence corroborates this potential. Timothy J. Besley and Harvey S. Rosen (1999) exploit regional differences in excise tax rates and retail prices across US states for a range of products sold at supermarkets, fast-food restaurants, and department stores, and they find evidence of overshifting for more than half the products in their sample. This empirical outcome is puzzling in light of tax theory with single-product firms. As Anderson, de Palma, and Brent Kreider (2001b) observe, the high degree of demand convexity necessary to generate the overshifting of excise taxes is ruled out by standard oligopoly assumptions; for instance, specific taxes are overshifted in the short run only when industry demand is steeper than marginal revenue, and ad valorem taxes are overshifted only when the marginal revenue curve for the industry demand curve slopes up instead of down.

I show here that quite the opposite is true with multiproduct firms. Under a mild regularity condition on consumer preferences for variety, excise taxes are shifted forward more than onefor-one into consumer prices in all cases except when demand is highly convex. The reason that overshifting readily occurs with multiproduct firms is that higher excise taxes cause firms to divest product variety, and this softens price competition and facilitates the overshifting of taxes into prices. Product divestiture does not happen when demand is highly convex, however, because the same forces that lead taxes to increase price-cost margins and raise profits for singleproduct firms now provide incentives for multiproduct firms to introduce new products. Price competition intensifies, and excise taxes are shifted forward less than one-for-one into consumer prices.

One of the oldest issues in the formal study of public finance is the comparison of ad valorem and specific forms of excise taxation. Following Wicksell's (1896) observation that ad valorem (percentage) taxes may have favorable efficiency properties relative to specific (unit) taxes in monopoly markets, Daniel B. Suits and Richard A. Musgrave (1953) formally derive this result by comparing aggregate welfare at tax positions that are equivalent in terms of the total tax yield. Delipalla and Keen (1992) extend this result to homogeneous product oligopoly markets with single-product firms and show that ad valorem taxes are welfare superior to equal-yield specific taxes in both the short-run and long-run market equilibrium. The reason for the superior performance of ad valorem taxes is that the tax bill is indexed to the market price under an ad valorem tax, and this makes residual demand functions (net of taxes) more price elastic, thereby narrowing equilibrium price-cost margins.

But narrow price-cost margins deter product introductions in multiproduct settings. I show that the relative performance of ad valorem and specific taxes depends on the extent to which consumer preferences for variety are increasing in per product consumption levels. If consumer preferences for variety are increasing in per product consumption levels (the usual case), the ability of ad valorem taxes to stimulate output relative to equal-yield specific taxes tempers the otherwise adverse implications of ad valorem taxes for product variety. The welfare superiority of ad valorem taxes over equal-yield specific taxes in multiproduct settings depends, accordingly, on whether consumer preferences for variety are "strongly increasing" in per product consumption levels.

Multiproduct transactions alter the market structure implications of excise taxes as well. When excise taxes are levied on single-product firms, Besley (1989) and Anderson, de Palma, and Kreider (2001b) demonstrate that excise taxes are shifted into prices in a greater range of cases in the long run than in the short run. The opposite is true with multiproduct firms. An increase in excise tax rates generally decreases the equilibrium breadth of product variety, which softens price competition and reduces the fixed costs associated with multiproduct entry. Firms enter the industry in the long run and, as a result, taxes are overshifted into prices in a larger range of cases in the short run than in the long run. Yet, entrants crowd out product variety, and this 
has negative welfare effects. In the penultimate section of this paper, I numerically examine the market outcomes in the case of constant elasticity of substitution (CES) preferences and find that aggregate welfare declines more sharply with excise taxes in the long run than in the short run. This suggests that the essential spirit of Besley's (1989) argument may be impervious to multiproduct transactions.

\section{The Model}

Consider an industry comprising $n$ multiproduct retailers. The retailers are differentiated in terms of their spatial proximity to consumers, and competition is localized in the sense that consumers compare only neighboring retailers in deciding where to shop. Each retailer is represented as a point on a circle of unit length and, following Salop (1979), the problem of location choice is suppressed: whatever the number of retailers happens to be, they are always equally spaced about the circle.

Consumers are distributed about the circle with a constant density per unit length and incur increasing transportation costs over distance to visit retailers. As in the spatial duopoly model of Robert Innes and Stephen F. Hamilton (2006), consumers purchase multiple products on each shopping occasion.

I consider the class of preferences, first analyzed by Spence (1976a,b, 1977) and Dixit and Stiglitz (1977) and subsequently pursued by Kai-Uwe Kühn and Xavier Vives (1999). Specifically, I describe preferences by the aggregate utility function $U(z, y)=G(z)+y$, where $z$ is a composite commodity and $y$ is the consumption level of a numeraire good. $G(z)$ is an increasing function with constant elasticity $(1-\varepsilon) \in(0,1)$, and the consumption level of the composite commodity $z$ is determined by the subutility function $z=\int_{i=0}^{\infty} f\left(x_{i}\right) d i$, where $x_{i}$ is the amount consumed of variety $i$ and $f(x)$ is a smooth, increasing, and strictly concave function for all $x>0$.

To develop observations on the effect of excise taxes on multiproduct retailers, it is necessary to characterize the intensity of preferences for product variety. This depends on the elasticities of $f(x)$ and $f^{\prime}(x)$. Let $\theta(x)=f^{\prime}(x) x / f(x)$ denote the elasticity of $f(x)$ and let $\gamma(x)=-x f^{\prime \prime}(x) / f^{\prime}(x)$ denote the elasticity of $f^{\prime}(x) .^{2}$

Inverse demand for variety $i$ for the representative consumer is

$$
p\left(z, x_{i}\right)=G^{\prime}(z) f^{\prime}\left(x_{i}\right)
$$

For symmetric allocations, inverse demand per product, $p(m, x)=G^{\prime}(m f(x)) f(x)$, is decreasing in $m$ and $x$. Specifically, the output elasticity of inverse demand with respect to price is $e^{p, x}(m, x)$ $=\sigma(x)$, where $\sigma(x) \equiv \gamma(x)+\theta(x) \varepsilon$, and the output elasticity of inverse demand with respect to product variety is $e^{p, m}(m, x)=\varepsilon$.

Equation (1) implicitly defines the demand functions for the representative consumer, $x_{i}(m, p)$, where $m$ is the number of products available at a given retailer and $p$ is the associated vector of prices. The demands can be used to recover indirect utility, $v(m, p)$. This allows:

\section{LEMMA 1: The effect of a change in product variety on consumer utility is}

$$
\frac{\partial v(m, p)}{\partial m}=\left(\frac{1-\theta\left(x_{m}\right)}{\theta\left(x_{m}\right)}\right) p_{m} x_{m} .
$$

\footnotetext{
${ }^{2}$ For symmetric solutions, $\gamma(x)$ is the inverse elasticity of substitution between any two goods.
} 
In a symmetric allocation, $1-\theta(x)$ measures the degree of consumer preference for variety. It is the proportion of social benefits not captured by revenues when a new product is introduced (i.e., $\left.1-G^{\prime} f^{\prime} x / G^{\prime} f=1-\theta(x)\right)$. Product variety is less valuable to consumers for larger values of $\theta(x)$, and the products are perfect substitutes (i.e., indifference contours are hyperplanes) as $\theta(x) \rightarrow 1$.

Aggregate demand facing the representative retailer depends on the decision made by consumers at each point on the circle regarding where to shop. Let $t$ denote consumer transportation cost per unit distance. A consumer at a distance of $\delta \in(0,1)$ from the representative retailer could achieve surplus of $v(m, p)-\delta t$ by purchasing from that retailer. If there are $n$ retailers located about the circle, for consumers located on the interval $0 \leq \delta \leq 1 / n$ between a retailer and his nearest neighbor, the surplus available by purchasing from the rival retailer is $v(\bar{m}, \bar{p})-$ $t(1 / n-\delta)$, where $v(\bar{m}, \bar{p})$ is indirect utility evaluated at the prices and product varieties of the rival. Let $\delta^{*}$ denote the location of the consumer who is indifferent between these two alternatives. Then $\delta^{*}$ solves $v(m, p)-\delta t=v(\bar{m}, \bar{p})-t(1 / n-\delta)$, or

$$
\delta^{*}(m, p ; \bar{m}, \bar{p})=\frac{1}{2 n}+\frac{1}{2 t}[v(m, p)-v(\bar{m}, \bar{p})] .^{3}
$$

All consumers located at a distance of $\delta \leq \delta^{*}$ prefer to shop with the representative retailer and more distant consumers prefer to shop with the rival.

Now consider the retailer's problem. Each retailer pays a fixed set-up cost, $F$, and a constant unit cost of $c$ to stock an individual product. All products are subject to taxation, and excise taxes are levied through some combination of specific tax rates $(\tau)$ and ad valorem tax rates $(\alpha)$. Variable profit per consumer (net of taxes) for the representative retailer is

$$
\pi^{m}(m, p)=\int_{i=0}^{\infty}\left((1-\alpha) p_{i}-c-\tau\right) x_{i}(m, p) d i
$$

and total profit is

$$
\Pi(m, p ; \bar{m}, \bar{p})=2 \delta^{*}(m, p ; \bar{m}, \bar{p}) \pi^{m}(m, p)-\int_{i=0}^{\infty} F d i
$$

Notice that the model produces a clear decomposition of profits into an interretailer margin and an intraretailer margin. On the interretailer margin, relative prices and the relative breadth of product variety across retailers shift consumers between the representative retailer and her rivals through the term $\delta^{*}(m, p ; \bar{m}, \bar{p})$. On the intraretailer margin, relative prices and the total amount of product variety available at a given retailer determine the allocation of sales per customer across products through the term $\pi^{m}(m, p)$.

The first-order necessary condition for profit maximization with respect to $p_{i}$ is

$$
\frac{-x_{i}}{t} \pi^{m}(m, p)+2 \delta^{*}(m, p ; \bar{m}, \bar{p})\left(\frac{\partial \pi^{m}(m, p)}{\partial p_{i}}\right)=0,
$$

\footnotetext{
${ }^{3}$ The focus of the paper is on established retail markets in which at least a subset of consumers are willing to switch between retailers on the basis of changes in relative prices and product variety. Accordingly, this formula and the ones that follow hold only in the range of interretailer competition $v(\bar{m}, \bar{p})-t / n<v(m, p)<v(\bar{m}, \bar{p})+t / n$. To avoid outcomes where an equilibrium may fail to exist, it is assumed that these inequalities are always met.
} 
where use has been made of Roy's identity in deriving the first term $\left(\partial \delta^{*} / \partial p_{i}=-x_{i} / 2 t\right)$. This is an intuitive condition. The first term on the left-hand side is the effect of price $i$ on the interretailer margin. A small increase in price of $d p_{i}$ units shifts $\left(x_{i} / t\right) d p_{i}$ consumers away from the retailer and toward her rivals. Because each consumer accounts for $\pi^{m}$ in multiproduct rents, the effect of the price increase on the interretailer margin is to reduce profits by $\left(x_{i} / t\right) \pi^{m} d p_{i}$ units. The second term on the left-hand side is the effect of an increase in price $i$ on the intraretailer margin. If faced with a constant number of customers $\left(\delta^{*}\right.$ given), the retailer would select multiproduct monopoly prices, $\partial \pi^{m} / \partial p_{i}=0$ for all $i$, to maximize rents on the intraretailer margin. When the number of customers is endogenous, retail prices are set below the monopoly price level, $\partial \pi^{m} / \partial p_{i}$ $>0$, because the first term on the left-hand side of equation (3) - the effect of the price increase on the number of customers-is negative.

Equation (3) provides a Ramsey-type rule for selecting a mix of price discounts to meet a desired price level on the intraretailer margin. Comparing this condition across any two products $i$ and $j, i \neq j$, retailers discount prices below the multiproduct monopoly level to maintain $x_{j} \partial \pi^{m} / \partial p_{i}=x_{i} \partial \pi^{m} / \partial p_{j}$.

Increased variety provision intensifies price competition. To see this, notice that the number of customers served by the representative retailer, $\delta^{*}(m, p ; \bar{m}, \bar{p})$, acts as an implicit weight on the intraretailer margin in the determination of equilibrium prices. Larger values of $\delta^{*}$ endow retailers with more customers, which weakens business-stealing incentives to discount retail prices. If a rival retailer extends her product line, the additional variety available at that retailer increases consumer utility from shopping with the rival, and this reduces the number of customers who shop with the representative firm. The retailer responds to the rival's increase in product variety by selecting lower prices on all products.

Variety choices are governed by the remaining first-order condition,

$$
\frac{p_{m} x_{m}}{t}\left(\frac{1-\theta\left(x_{m}\right)}{\theta\left(x_{m}\right)}\right) \pi^{m}(p, m)+2 \delta^{*}(p, m ; \bar{p}, \bar{m})\left(\frac{\partial \pi^{m}(p, m)}{\partial m}\right)-F=0,
$$

where use has been made of Lemma 1 in deriving the first term. This condition has a similar interpretation as equation (3). The latter two terms on the left-hand side of (4) describe the optimal provision of product variety for a retailer facing a given number of consumers. A monopoly retailer would set the sum of these terms equal to zero. The first term on the left-hand side of (4) is the effect of introducing a new product on the interretailer margin. The effect is positiveproviding greater product variety attracts customers away from rivals - and this leads oligopoly retailers to provide wider product ranges than would be the case under monopoly.

Notice that the outcome for the retail oligopoly equilibrium depends only on the strategic interaction of prices and variety selection on the interretailer margin of these equations. Each consumer considers the utility level that can be derived from retailers at the available product ranges and prices and decides where to shop. This implies the rather convenient property that the equilibrium of the multiproduct oligopoly model does not depend on whether retailers select prices $(p)$ or per product output levels $(x)$. Nevertheless, because it is helpful for expositional purposes to consider the market conditions as implicit functions of $x$ and $m$, I express retail prices hereafter in terms of $m$ and $x$ to motivate this interpretation. ${ }^{4}$

The equilibrium price per product, $p_{e}$, and the equilibrium number of products, $m_{e}$, in the short-run allocation are determined by the simultaneous solution of equations (3) and (4). The

\footnotetext{
${ }^{4}$ I elaborate on these details in the online Appendix (available at http://www.aeaweb.org/articles.php?doi=10.1257/ aer.99.1.458).
} 
long-run equilibrium $\left(p_{c}, m_{c}, n_{c}\right)$ is determined by these two equations and the entry condition, which states that profits are zero. In the symmetric case, this implies

$$
((1-\alpha) p(m, x)-c-\tau) \frac{x}{n}-F=0
$$

\section{Changes in Excise Tax Rates}

Central to the analysis of the equilibrium effects of excise taxes is how consumer preferences for product variety are influenced by changes in the level of consumption per product. This is measured by the elasticity of $\theta(x)$,

$$
e^{\theta}(x)=\theta^{\prime}(x) x / \theta(\mathrm{x})
$$

In his excellent survey of the Chamberlinian model, Vives $(1999,171)$ refers to the case of $e^{\theta}(x)$ $<0$ as "increasing preferences for variety" and describes this outcome to be the normal case. When $e^{\theta}(x)<0$ at $x$, an additional product provides greater utility on the margin at high levels of per product consumption than at low levels of per product consumption.

To better understand consumer preferences for variety, it is helpful to express this term as $e^{\theta}(x)$ $=\beta(x)-\sigma(x)$, where $\beta(x)=1-(1-\varepsilon) \theta(x) . \beta(x)$ can be interpreted as the net effect of a product introduction on consumer surplus, taking into account the effect of the change in product variety on per product inverse demand. When $\varepsilon=0$, demand per product is perfectly elastic in $m$, so that the introduction of a new product does not alter the valuation of existing products, $\beta(x)$ $=1-\theta(x)$. When $\varepsilon>0$, new products cannibalize a portion of their sales from demand for existing products (the shift in the $d d$ curve in Chamberlinian terminology). The cannibalization of sales from existing products when a new product is introduced reduces the proportion of social benefits captured by revenues on existing products.

The difference, $\beta(x)-\sigma(x)$, gives the sign of the change in consumer surplus that would arise from a marginal reallocation between the number of products and output per product at a given level of consumption. ${ }^{5}$ Increasing preferences for variety, $e^{\theta}(x)<0$, implies that consumer surplus rises at $x$ with a change in market composition toward higher output per product and a smaller variety range.

The degree to which consumer preferences for variety are increasing in consumption levels has important implications for the relative efficiency of ad valorem and specific taxes. Define consumer preferences for variety to be "strongly increasing" at $x$ if

$$
\lambda(x) \equiv e^{\theta}(x)+\frac{(1-\varepsilon)(1-\theta(x)) \theta(x) \sigma(x) \varepsilon}{\beta(x)}<0 .
$$

It is well known in the single-product case that the effect of excise taxes on the market equilibrium depends on the elasticity of the slope of inverse demand, $E \equiv-p_{x x} x / p_{x}$. This is true in

\footnotetext{
${ }^{5}$ Formally, let $s(m, x)=G(z(m, x))-p(m, x) m x$ denote consumer surplus in the symmetric allocation, and consider changes in the consumption level of the composite commodity that satisfy $d z=f(x) d m+m f^{\prime}(x) d x=0$. This yields
}

$$
\left.\frac{d s(x, m)}{d x}\right|_{d z=0}=m p(m, x)[\sigma(x)-\beta(x)] .
$$


the multiproduct case as well. Before deriving specific propositions from the present model, it is helpful to restrict attention to cases in which per product demand functions are not too convex:

ASSUMPTION 1. $E \leq 2$.

ASSUMPTION 2. $2 \varepsilon \geq 1$.

Assumption 1 rules out cases in which marginal revenue functions slope upward. Assumption 2 ensures that the subutility function of the representative consumer is strictly concave at symmetric allocations for arbitrarily small values of $\gamma(x) .{ }^{6}$ Together with increasing preferences for variety, $e^{\theta}(x)<0$, these assumptions guarantee that single-firm and industry profits are concave in $x$ and $m$. $^{7}$

In oligopoly models with single-product firms, excise taxes reduce output, increase prices, and precipitate the exit of firms in the long run. The following result characterizes the market outcomes in settings with multiproduct firms.

PROPOSITION 1: If $e^{\theta}(x) \leq 0$, an increase in excise taxes in the short run:

(i) Reduces equilibrium output per product;

(ii) Narrows the equilibrium range of product variety; and

(iii) Increases prices per product.

If $e^{\theta}(x) \leq 0$, an increase in excise taxes in the long run:

(i) Reduces equilibrium output per product in the case of specific taxes, but increases equilibrium output per product in the case of ad valorem taxes;

(ii) Narrows the equilibrium range of product variety;

(iii) Increases prices in the case of specific taxes and increases prices in the case of ad valorem taxes when $\sigma\left(x^{c}\right)>1$; and

(iv) Stimulates entry of multiproduct retailers.

When excise taxes are levied on multiproduct retailers, an increase in tax rates narrows the equilibrium range of product variety. This softens price competition and facilitates retailer entry by reducing the fixed costs of maintaining the equilibrium product assortment. While it is conceivable for prices to decrease in response to ad valorem taxes when retailers operate on the elastic portion of per product demand functions $\sigma(x)<1$, such an outcome for prices is possible only for parameterizations of the model that involve highly convex demand combined with constant or weakly increasing preferences for variety. In the case of CES preferences, which satisfies all these conditions, the long-run equilibrium price per product increases with ad valorem taxes.

In single-product oligopoly markets, it is well known that excise taxes are overshifted into prices when demand is sufficiently convex. Besley and Rosen (1999) find empirical support for

\footnotetext{
${ }^{6}$ That is, $G_{x x} G_{m m}-G_{m x} G_{x m} \stackrel{s}{=}(2 \varepsilon-1) \theta(x)+\gamma(x) \varepsilon$, where "s $=$ " denotes "equals in sign."

${ }^{7}$ For details, see Lemma A1 in the online Appendix.
} 
the overshifting of taxes on commonly purchased retail products such as bananas, bread, shampoo, milk, and soda. This evidence is puzzling in light of the critique by Anderson, de Palma, and Kreider (2001b) that the degree of demand convexity necessary to generate the overshifting of taxes is ruled out by standard assumptions of oligopoly models. In the short run, Seade (1987) demonstrates that specific taxes are overshifted into prices when $E>1$, which implies that the industry marginal revenue curve is steeper than demand, and Delipalla and Keen (1992) show that ad valorem taxes are overshifted into prices when $E>2$, which implies that the marginal revenue curve associated with industry demand slopes up instead of down.

The opposite is true in multiproduct retail environments.

PROPOSITION 2: If $e^{\theta}(x) \leq 0$, in the short run:

(i) Specific taxes are overshifted into prices when $E<1+\varepsilon+\sigma(x) / \beta(x)$; and

(ii) Ad valorem taxes are overshifted into prices when $E<1+\sigma(x)-(\theta(x) \sigma(x)) / \beta(x)$.

If $e^{\theta}(x) \leq 0$, in the long run:

(i) Specific taxes are overshifted into prices when $E<1+2 \varepsilon$; and

(ii) Ad valorem taxes are overshifted into prices when $E<1+\sigma(x)$.

When consumers have increasing preferences for variety, excise taxes are shifted forward more than one-for-one into consumer prices in multiproduct retail environments with linear or concave demand, and can be undershifted only when demand is highly convex. The reason that excise taxes are overshifted in a wide range of cases is that retailers generally respond to higher taxes by narrowing their variety ranges, which softens price competition and facilitates the shifting of taxes into consumer prices. But under the highly convex demand conditions associated with increased price-cost margins and larger profits in response to higher excise tax rates on single-product firms, an increase in excise taxes provides multiproduct firms with an incentive to introduce new products. This intensifies price competition and leads excise taxes to shift less than one-for-one into prices.

COROLLARY 1: If $e^{\theta}(x) \leq 0$, excise taxes overshift into prices in a wider range of cases in the short run than in the long run.

With single-product retailers, Besley (1989) and Anderson, de Palma, and Kreider (2001b) demonstrate that excise taxes are more likely to be overshifted into consumer prices in the long run than in the short run. The opposite occurs with multiproduct firms. Entry occurs in response to higher excise tax rates, and this places greater competitive pressure on prices in the long-run market equilibrium.

\section{Welfare Analysis}

When excise taxes are levied on multiproduct transactions, taxes influence consumer utility by altering the market provision of output and product variety. In the long run, taxes also alter consumer transportation costs by changing the number of firms. In this section, I first examine the implications of excise taxes for economic efficiency, as measured by the change in aggregate welfare following an increase in excise tax rates. I then consider the relative efficiency of 
ad valorem and specific taxes by calculating the effect of tax reforms that shift the balance of taxation between the two instruments while maintaining a constant tax yield. In each case, the interaction effects of preexisting taxes are suppressed for expositional purposes by evaluating all effects at an initial zero tax position $(\alpha=\tau=0) .{ }^{8} \mathrm{I}$ complement this approach in the next section by using numerical techniques to examine the market equilibrium at positive levels of tax revenue.

I take aggregate welfare to be the sum of consumer surplus and producer surplus in the market. Consider, first, the short-run market equilibrium. Letting $\phi=(\alpha, \tau)$ denote the vector of policy variables, aggregate welfare at a symmetric allocation is given by

$$
W(\phi)=G(m(\phi) f(x(\phi)))+y-m(\phi)(c x(\phi)+n F)-\frac{t}{4 n} \cdot 9
$$

The final term in the welfare expression represents consumer transportation cost, where $\bar{\delta}=1 / 4 n$ is the average traveling distance between consumers and retailers in the symmetric equilibrium. This cost is constant in the short run, and the welfare change with respect to a change in the rate of excise taxation, accordingly, is

$$
\frac{\partial W(\phi)}{\partial \phi}=m[(p(m, x)-c)] \frac{\partial x}{\partial \phi}+\left[\left(\frac{p(m, x)}{\theta(x)}-c\right) x-n F\right] \frac{\partial m}{\partial \phi}
$$

At the socially optimal resource allocation $\left(m^{*}, x^{*}\right)$, each of the terms in square brackets equates with zero. By inspection of terms, output per product at the social optimum satisfies $p\left(m^{*}, x^{*}\right)$ $=c$. Product variety at this price level is provided to equate the marginal utility of variety, $((1-\theta) / \theta) c x^{*}$, with the marginal cost of distributing a new product across retailers in the market, $n F$.

In general, the market equilibrium diverges from the social optimum as the result of two distortions. The first distortion is an appropriability effect. Retailers in the market fail to fully acquire the rents from the sale of products to consumers, and this deters output per product (variety given) and dampens the incentive to introduce new varieties (output given). The appropriability effect leads the market to provide a smaller breadth of product variety and lower output levels than in the socially optimal resource allocation. The second distortion is the businessstealing externality. When selecting a mix of product variety and prices, retailers fail to account for the negative effects of lower prices and improved product assortments on the sales made by rival retailers. The business-stealing effect leads the market to provide larger variety ranges and higher output levels than is optimal. The market allocation diverges from the social optimum according to the relative gravitation of these effects.

I evaluate the implication of excise taxes on aggregate welfare at the market equilibrium position. The qualitative effects of excise taxes on aggregate welfare do not depend on the explicit values of $n$; however, it is analytically convenient to examine these effects at the zero profit position $\left(m^{e}\left(n^{c}\right), x^{e}\left(n^{c}\right)\right)$. Making use of equations (3)-(5), inverse demand per product in the market equilibrium satisfies

\footnotetext{
${ }^{8}$ In the case of equal-yield tax reforms that exchange specific taxes for ad valorem taxes, this implies examining combinations of positive ad valorem taxes and negative specific taxes (subsidies).

${ }^{9}$ This formulation assumes that the tax revenue collected by the regulator is a pure transfer that is unrelated to the welfare outcome.
} 


$$
p(x)=\frac{(c+\tau) \beta(x)}{(1-\alpha) k(x)}
$$

where $k(x)=\beta(x)-(1-\theta(x)) \sigma(x)>0$. Substituting this value into equation (6), the efficiency implications of excise taxes at the zero tax position are characterized by

$$
\frac{\partial W(\phi)}{\partial \phi}=\frac{(1-\theta(\mathrm{x})) c m x}{k(x)}\left[\frac{\sigma(x)}{x} \frac{\partial x}{\partial \phi}+\frac{\beta(x)}{\theta(x) m} \frac{\partial m}{\partial \phi}\right] .
$$

Notice that aggregate welfare is increasing both in output per product and in the variety range. It follows from Proposition 1 that an increase in excise tax rates unambiguously harms welfare when consumer preferences are increasing in variety.

In the long-run market equilibrium, welfare at a symmetric allocation is given by

$$
W(\phi)=G(m(\phi) f(x(\phi)))+y-m(\phi)(c x(\phi)+n(\phi) F)-\frac{t}{4 n(\phi)} .
$$

The marginal benefit of an additional retailer in the aggregate welfare calculation is the reduction in consumer transportation costs, $t /\left(4 n^{2}\right)$. The marginal cost of an additional retailer is the expense of providing the product assortment, $m F$, and the socially optimal number of retailers is selected to equate these terms.

The number of retailers operating in the market equilibrium generally differs from the socially optimal number according to the relative magnitude of the appropriation effect and the businessstealing effect discussed above. For the case of CES preferences, which I examine below, retailers in the market equilibrium undersupply product variety, and the number of firms is excessive from the social perspective.

Differentiating the welfare expression with respect to the policy variable $(\phi)$ and making use of terms from the market equilibrium $\left(m^{c}, n^{c}, x^{c}\right)$ gives

$$
\frac{\partial W(\phi)}{\partial \phi}=\frac{(1-\theta) c m x}{k(x)}\left[\frac{\sigma(x)}{x} \frac{\partial x}{\partial \phi}+\frac{\beta(x)}{\theta(x) m} \frac{\partial m}{\partial \phi}+\frac{(\beta(x)-4 \theta(x) \varepsilon) \sigma(x)}{4 \theta(x) \varepsilon n} \frac{\partial n}{\partial \phi}\right] .
$$

Under conditions of free-entry, policies that increase output and widen the breadth of product variety lead to an improved resource allocation; policies that increase the number of firms improve aggregate welfare when $\beta(x)>4 \theta(x) \varepsilon$.

PROPOSITION 3: If $e^{\theta}(x) \leq 0$, an increase in excise taxes at the zero tax position harms aggregate welfare in both the short-run and the long-run market equilibrium.

One of the oldest issues in the study of public finance is the comparison of ad valorem and specific forms of taxation. In homogeneous product oligopoly markets with single-product firms, it is well known that ad valorem taxes welfare dominate specific taxes. The reason is that ad valorem taxes make after-tax residual demand functions more elastic, and this narrows equilibrium price-cost margins in the market. In differentiated product environments, Anderson, de Palma, and Kreider (2001a) show that ad valorem taxes have adverse effects on product variety relative to specific taxes when single-product firms operate under a fixed aggregate output constraint. In settings where output and product variety decisions are jointly determined, intuition 
might suggest that the use of ad valorem taxes introduces a trade-off in consumer utility functions between higher output levels and lower variety ranges relative to specific taxes. But this is not so. When consumer preferences for product variety are increasing in per product consumption levels, ad valorem taxes can lead to superior outcomes for both output and product variety than equal-yield specific taxes.

To see this, consider an arbitrary tax reform between ad valorem and specific tax instruments that preserves the existing tax yield. For any combination of excise tax rates, the total tax yield is $T=(\alpha \tilde{p}+\tau) \tilde{m} \tilde{x}$, where $\tilde{p}=p^{e}, \tilde{m}=m^{e}$, and $\tilde{x}=x^{e}$ in the short run and $\tilde{p}=p^{c}, \tilde{m}=m^{c}$, and $\tilde{x}$ $=x^{c}$ in the long run. Differentiating these expressions and evaluating terms at an initial zero tax position, ${ }^{10}$ a revenue-neutral shift from specific taxes to ad valorem taxes satisfies

$$
\left.\frac{d \tau}{d \alpha}\right|_{T=0}=-\tilde{p} .
$$

PROPOSITION 4: If $e^{\theta}(x) \leq 0$, a revenue-neutral shift from specific taxes toward ad valorem taxes at an initial zero tax position:

(i) Increases equilibrium output per product;

(ii) Increases the equilibrium range of product variety in the short run when $e^{\theta}(x) \leq$ $-\varepsilon \theta(x) \sigma(x)$ and in the long run when $e^{\theta}(x) \leq-\varepsilon^{2} \theta(x)$;

(iii) Leads to exit of retailers in the long run when $\lambda(x)<0$; and

(iv) Leads to an improved aggregate welfare allocation when $\lambda(x)<0$.

Conversely, specific taxes welfare dominate ad valorem taxes for a range of parameterizations of the model when $\lambda(x) \geq 0$. Such an outcome is more likely to occur when consumer preferences for variety are nonincreasing in $x$ and when per product demand functions are highly convex, conditions that hold in the case of CES preferences I examine below.

\section{Example: CES Preferences}

I consider here the case in which preferences for the composite commodity are characterized by constant elasticity of substitution (CES), $z=\int_{i=0}^{\infty} x_{i}^{\theta} d i$ with $0<\theta \leq 1$ given. For the CES class of preferences, consumer preferences for variety are constant with respect to changes in $x$ and $E=2-(1-\varepsilon) \theta$.

I numerically examine equal-yield tax positions for the subutility function $G(z)$ $=A\left(\int_{i=0}^{\infty} x_{i}^{\theta} d i\right)^{1-\varepsilon}$. This allows the outcomes of the numerical model to be compared for combinations of ad valorem and specific taxes that correspond to identical tax yields after accounting for the equilibrium adjustments in the endogenous variables that take place in response to taxes. Parameter values in the baseline calibration of the model are $A=1, \varepsilon=0.5, \theta=0.5, c=0.5, F$ $=0.01, t=1$, and, in the short-run model, $n=2$ (duopoly).

\footnotetext{
${ }^{10}$ Evaluating equal-yield tax reforms at the initial zero tax position is consistent with the approach taken by Besley (1989) and corresponds to the concept of "P-shifts" examined by Delipalla and Keen (1992). Suppressing second-order effects on tax revenue that arise through equilibrium responses to marginal changes in the composition of excise taxes clarifies the results by providing a smaller apparatus to sift through. In the Section IV, I numerically examine equalyield tax positions at positive revenue levels and account for equilibrium adjustments in the market variables.
} 
TABle 1-Equal-Yield Tax Comparison In the Short Run

\begin{tabular}{lccccccc}
\hline \hline Revenue & \multicolumn{2}{c}{ Tax instrument } & \multicolumn{5}{c}{ Equilibrium value } \\
& Ad valorem & Specific & $p$ & $m$ & $x$ & $\Pi / n$ & $W$ \\
\hline$T=0.00$ & - & - & 1.03 & 7.33 & 0.040 & 0.0048 & 0.792 \\
$T=0.01$ & $\alpha=0.035$ & - & 1.09 & 6.57 & 0.040 & 0.0067 & 0.759 \\
& $\overline{-}$ & $\tau=0.040$ & 1.14 & 6.79 & 0.037 & 0.0071 & 0.756 \\
$T=0.02$ & $\alpha=0.074$ & - & 1.16 & 5.82 & 0.040 & 0.0085 & 0.721 \\
& - & $\tau=0.097$ & 1.29 & 6.14 & 0.034 & 0.0097 & 0.709 \\
$T=0.03$ & $\alpha=0.120$ & - & 1.25 & 5.00 & 0.040 & 0.0100 & 0.675 \\
& - & $\tau=0.200$ & 1.57 & 5.25 & 0.029 & 0.0127 & 0.637 \\
\hline
\end{tabular}

Table 2-EQual-Yield Tax Comparison In the Long Run

\begin{tabular}{lccccccc}
\hline \hline Revenue & \multicolumn{2}{c}{ Tax instrument } & \multicolumn{5}{c}{ Equilibrium value } \\
& Ad valorem & Specific & $p$ & $m$ & $x$ & $n$ & $W$ \\
\hline$T=0.00$ & - & - & 1.00 & 6.44 & 0.046 & 2.28 & 0.769 \\
$T=0.01$ & $\alpha=0.037$ & - & 1.04 & 5.34 & 0.049 & 2.45 & 0.723 \\
& - & $\tau=0.040$ & 1.08 & 5.52 & 0.046 & 2.46 & 0.722 \\
$T=0.02$ & $\alpha=0.081$ & - & 1.09 & 4.22 & 0.054 & 2.69 & 0.670 \\
& - & $\tau=0.098$ & 1.20 & 5.51 & 0.046 & 2.72 & 0.664 \\
$T=0.03$ & $\alpha=0.138$ & - & 1.16 & 3.07 & 0.061 & 3.06 & 0.602 \\
& - & $\tau=0.202$ & 1.40 & 3.27 & 0.046 & 3.19 & 0.578 \\
\hline
\end{tabular}

Table 1 reports the short-run outcomes for prices, variety, output, profits, and welfare under combinations of ad valorem and specific taxes that attain a given government revenue target. The entries in Table 1 indicate that prices and profits rise with the level of the tax collection, while output, variety, and aggregate welfare decline. Ad valorem taxes welfare dominate equal-yield specific taxes in all cases. This is true despite the fact that consumer preferences for variety are constant and demand is highly convex $(E=1.75)$, conditions that tend to favor specific taxes. This outcome suggests the use of ad valorem taxes as a rule of thumb in markets with multiproduct transactions.

Table 2 presents the long-run effects of excise taxes. The entries indicate a similar qualitative pattern in the market response to excise taxation as in the short run, with the exception that taxes result in per product output levels that are (at least weakly) increasing at higher levels of tax revenue. A comparison of the entries in Tables 1 and 2 reveals the superior efficiency of excise tax policy in the short run: in all cases, higher tax rates are required for the regulator to attain a given revenue target in the long run than in the short run. For a given tax yield, aggregate welfare correspondingly declines by more in the long run than in the short run. For instance, to attain the $T=0.01$ tax level, welfare declines 4.2 percent from the pre-tax position with ad valorem taxes in the short run and declines 6.0 percent with ad valorem taxes in the long run. Excise taxes are overshifted into prices to a greater degree in the short run than in the long run, but taxes reduce product variety to a greater degree in the long run. The combination of these effects leads to inferior welfare performance of excise taxes in the long run. This suggests that the essential spirit of Besley's (1989) argument may be immune to the specification of multiproduct transactions.

\section{Conclusion}

In this paper I have extended the analysis of excise taxes to consider the case of multiproduct transactions. Under circumstances in which consumer preferences for variety are increasing in per product consumption levels, excise taxes reduce output and product variety in the short run; 
however, ad valorem taxes raise output per product in the long run and both ad valorem and specific taxes facilitate the entry of multiproduct firms.

Excise taxes have substantially different implications for market performance in settings with multiproduct firms. With single-product firms, taxes are shifted forward into consumer prices more than one-for-one when demand is highly convex, and are more likely to be overshifted in the long run than in the short run. With multiproduct firms, taxes are more likely to overshift into prices when demand is concave than when demand is convex, and the extent to which taxes are shifted into consumer prices is mitigated in the long run with entry.

The relative efficiency of ad valorem and specific forms of excise taxes in multiproduct environments depends on the extent to which consumer preferences for variety are altered by changes in per product output levels. The superior ability of ad valorem taxes to preserve equilibrium output levels vis-à-vis equal-yield specific taxes is offset in the case of multiproduct transactions by potentially detrimental effects of ad valorem taxes on product variety provision. When consumer preferences are strongly increasing in consumption levels, the ability of ad valorem taxes to stimulate output relative to equal-yield specific taxes tempers the adverse variety effects of excise taxes, and ad valorem taxes welfare dominate specific taxes; however, the converse is also true. Specific taxes welfare dominate ad valorem taxes that are equal in terms of total tax yield for a range of parameterizations of the model. Such an outcome is more likely when preferences for variety are constant or weakly increasing in per product consumption levels and when demand is highly convex.

There are numerous practical reasons why tax reforms frequently favor the use of ad valorem taxes over unit taxes; for instance, ad valorem taxes automatically adjust to inflation and can simplify problems of international tax coordination. These practicalities exist and are perhaps even more compelling in settings with multiproduct transactions. The relative efficiency of alternative forms of excise taxes in multiproduct contexts warrants greater attention as globalization increases the reach of retailers in providing product variety to consumers.

The multiproduct oligopoly framework developed in this paper can be readily extended to consider other policy questions. In particular, the model has a natural extension to international trade policy. The locational framework pursued here provides a clear decomposition between the variety-based motivations for gainful trade considered by Paul R. Krugman (1980) and the spatial patterns of cross-border trade that emerge in Ravi Kanbur and Keen (1993). International tax differentials have important implications for cross-border trade in practice, and the potential for transactions to occur simultaneously in multiple products produces economies of scope in consumer transaction cost functions. Multiproduct settings with endogenous variety selection are therefore likely to intensify tax competition by increasing the international movement of tax bases that arise from given indirect tax differentials, which, in turn, can alter the ability of governments to design credible rent-shifting policies. Ignoring the multiproduct nexus between taxes and trade, among other things, is thus likely to understate the gains from international tax coordination.

\section{REFERENCES}

Anderson, Simon P., and André de Palma. 2006. “Market Performance with Multiproduct Firms.” Journal of Industrial Economics, 54(1): 95-124.

Anderson, Simon P., André de Palma, and Brent Kreider. 2001a. "The Efficiency of Indirect Taxes under Imperfect Competition." Journal of Public Economics, 81(2): 231-51.

Anderson, Simon P., André de Palma, and Brent Kreider. 2001b. "Tax Incidence in Differentiated Product Oligopoly." Journal of Public Economics, 81(2): 173-92.

Besley, Timothy. 1989. "Commodity Taxation and Imperfect Competition: A Note on the Effects of Entry." Journal of Public Economics, 40(3): 359-67. 
Besley, Timothy J., and Harvey S. Rosen. 1999. "Sales Taxes and Prices: An Empirical Analysis.” National Tax Journal, 52(2): 157-78.

Cournot, Augustin. 1838. Recherches sur les pricipes mathématiques de la théorie des richesses [Research into the mathematical principles of the theory of wealth].New York: Macmillan, 1987.

Delipalla, Sofia, and Michael Keen. 1992. "The Comparison between Ad Valorem and Specific Taxation under Imperfect Competition." Journal of Public Economics, 49(3): 351-67.

Dixit, Avinash K., and Joseph E. Stiglitz. 1977. "Free Entry Oligopoly and Optimum Product Diversity." American Economic Review, 67(3): 297-308.

Innes, Robert, and Stephen F. Hamilton. 2006. "Naked Slotting Fees for Vertical Control of Multi-Product Retail Markets." International Journal of Industrial Organization, 24(2): 303-18.

Kanbur, Ravi, and Michael Keen. 1993. "Jeux Sans Frontières: Tax Competition and Tax Coordination when Countries Differ in Size.” American Economic Review, 83(4): 877-92.

Krugman, Paul. 1980. "Scale Economies, Product Differentiation, and the Pattern of Trade." American Economic Review, 70(5): 950-59.

Kühn, Kai-Uwe, and Xavier Vives. 1999. "Excess Entry, Vertical Integration, and Welfare.” RAND Journal of Economics, 30(4): 575-603.

Lancaster, Kelvin. 1975. "Socially Optimal Product Differentiation." American Economic Review, 65(4): $567-85$.

Salop, Steven C. 1979. "Monopolistic Competition with Outside Goods." Bell Journal of Economics, 10(1): $141-56$.

Seade, Jesus, K. 1987. "Profitable Cost Increases and the Shifting of Taxation: Equilibrium Responses of Markets in Oligopoly." Unpublished.

Spence, Michael. 1976a. "Product Differentiation and Welfare." American Economic Review, 66(2): 407-14.

Spence, Michael. 1976b. "Product Selection, Fixed Costs, and Monopolistic Competition." Review of Economic Studies, 43(2): 217-35.

Spence, A. Michael. 1977. “Nonprice Competition.” American Economic Review, 67(1): 255-59.

Stern, Nicholas H. 1987. "The Effects of Taxation, Price Control and Government Contracts in Oligopoly and Monopolistic Competition." Journal of Public Economics, 32(2): 133-58.

Suites, Daniel B., and Richard A. Musgrave. 1953. "Ad Valorem and Unit Taxes Compared." Quarterly Journal of Economics, 67(4): 598-604.

Vives, Xavier. 1999. Oligopoly Pricing: Old Ideas and New Tools. Cambridge, MA: MIT Press.

Wicksell, Knut. 1896. "Taxation in the Monopoly Case." In Readings in the Economics of Taxation, ed. Richard A. Musgrave and Carl Shoup, 156-77. Irwin, OH: Homewood Press, 1959. 